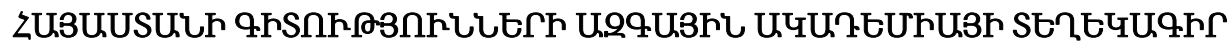 ИЗВЕСТИЯ НАЦИОНАЛЬНОЙ АКАДЕМИИ НАУК АРМЕНИИ
}

\author{
Uthaukipluw \\ 69, №4, 2016 \\ Механика

\section{УДК 539.3 \\ ON THE INFLUENCE OF BOUNDARY CONDITIONS ON THE DEPENDENCE AMPLITUDE-FREQUENCY OF NON-LINEAR FLUTTER TYPE OSCILLATIONS OF RECTANGULAR PLATE AT CRITICAL SPEED}

\section{Saghoyan R.O.}

Ключевые слова: Гибкие пластинки, сверхзвуковой поток газа, амплитудно-частотная зависимость. Keywords: Flexible plates; supersonic gas flow; dependence amplitude-frequency.

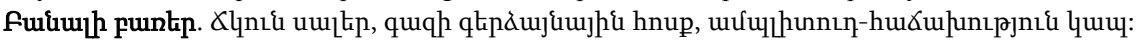

Сагоян P.O.

О влиянии граничных условий на амплитудно-частотную зависимость нелинейных флаттерных колебаний прямоугольной пластинки при критических скоростях

Рассматривается задача нелинейных колебаний изотропной прямоугольной пластинки, обтекаемой сверхзвуковым потоком газа. Исследование проведено с учётом обоих типов нелинейности: аэродинамической (квадратичной и кубической) и геометрической (кубической). Известно, что зависимость частоты нелинейных колебаний пластинки от амплитуды в отсутствии обтекающего потока носит жёсткий характер, т.е. с увеличением амплитуды частоты колебаний возрастают. В настоящей работе установлено, что присутствие обтекающего потока может стать источником как количественного, так и качественного изменения характера указанной монотонно возрастающей зависимости. В работе исследуется влияние типа закрепления границы пластинки в тангенциальных направлениях на амплитудно-частотную зависимость нелинейных флаттерных колебаний шарнирно опёртой по всему контуру прямоугольной пластинки при критической скорости потока. Показано, что переход из одного типа амплитудно-частотной зависимости к другому можно регулировать соответствующим выбором как геометрических и физических параметров аэроупругой системы, так и за счёт изменения краевых условий.

$$
\text { Uunnjuiq ก.O. }
$$

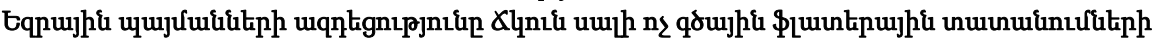

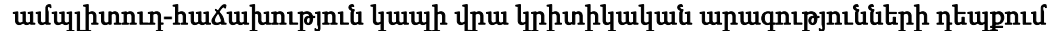

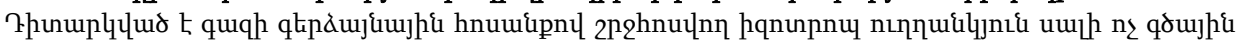

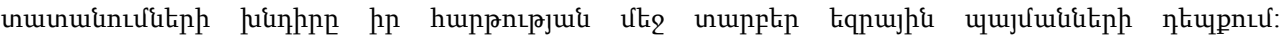

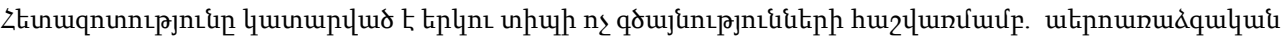

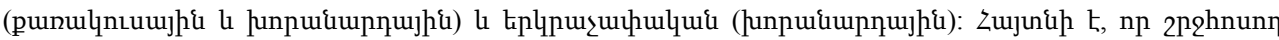

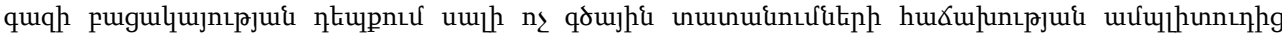

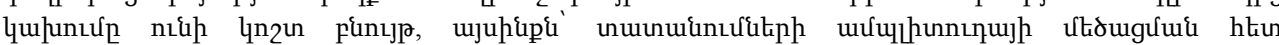

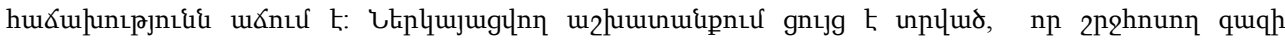

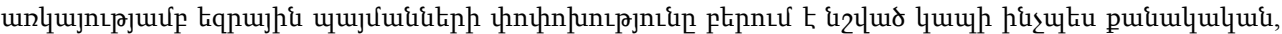

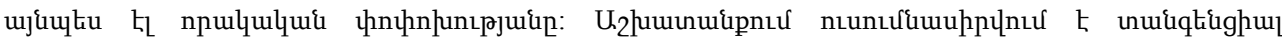

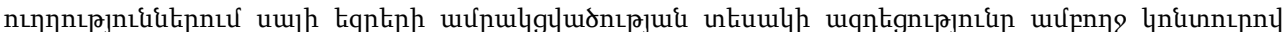

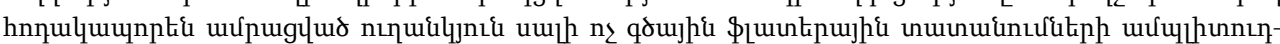
hux

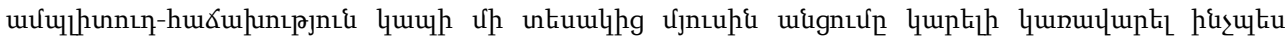

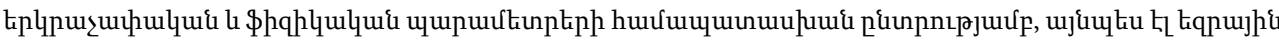

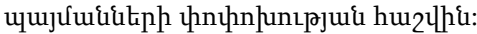


The problem of nonlinear oscillations of an isotropic rectangular plate in a supersonic gas flow is examined. The study was conducted taking into account both types of nonlinearities: wind (quadratic and cubic) and geometric (cubic). It is known that nonlinear dependence of the frequency on the amplitude of the oscillations of the plate in absence of flowing stream has a hard character, i.e. with increasing amplitude the frequency increases. In this paper it is established that the presence of flowing stream may cause both quantitative and qualitative changes of the character of noted monotonically increasing dependence. The influence of boundary conditions along the tangential directions of simply supported plate on the dependence amplitude-frequency of non-linear flutter type oscillations at critical speeds is investigated in this paper. It is shown that transmission from one type of examined dependence to another can be controlled as via the appropriate choice of both geometrical and physical parameters of aeroelastic system, as well as via the change of boundary conditions.

\section{Introduction}

There are many investigations devoted to the study of stability of plates and shells in supersonic gas flow [1-5]. A short review of up-to-date known results is brought in the work [6]. Let us note here the results devoted to the present work only. In the work [5] the dependence «amplitude-frequency» of non-linear flutter type oscillations is studied in the case of critical value of flowing speed. It was shown, that a) due to the aerodynamic nonlinearity (especially its non-symmetrical quadratic part) character of the dependence «amplitude-frequency» of non-linear flutter type oscillations of the plate in a supersonic gas flow is similar to the character of noted dependency of non-linear natural oscillations of shells; b) the range of variation of allowable frequencies at which it is possible to excite flutter type oscillations can be as finite, as well as semi-infinite; c) transition from one type of «amplitude-speed» dependency into another (up to the impossibility of excitation of such oscillations) can be controlled with an appropriate choice of the geometrical and physical parameters of the considered aeroelastic system, depending on the flow speed.

The influence of boundary conditions along the tangential directions of simply supported plate on the dependence amplitude-frequency of non-linear flutter type oscillations at critical speeds is investigated in this paper. It is shown that

- The choice of the type of boundary conditions in the presence of flowing stream may bring to the both quantitative and qualitative change the character of the noted monotone increasing dependence;

- Transmission from one type of examined dependence to another can be controlled as via the appropriate choice of both geometrical and physical parameters of aeroelastic system, as well as via the change of boundary conditions.

\section{Stability Problem formulation}

The problem is formulated by considering a thin isotropic rectangular plate of constant thickness $h$. It is referred to the Cartesian coordinate plane $\alpha, \beta, \gamma$ and the coordinate plane $\alpha, \beta$ coincides with the middle plane of the plate, and the coordinate lines $\alpha$ and $\beta$ are directed along the edges of the considered plate. A supersonic gas flow with freestream velocity magnitude $\vec{u}$, is aligned with the axis $0 \alpha$, on one side of the panel only. A supersonic gas flow with freestream velocity magnitude $\vec{u}$, is aligned with the axis $0 \alpha$, on one side of the panel only.

The initial assumptions for mathematical modeling and investigation of the examined problem are brought in the work [6]. Here, in addition to the brought in the noted work stability equations, let's formulate the boundary conditions only:

for $\alpha=0, \alpha=a$ 
$w=0, \quad M_{\alpha}=-D\left(\frac{\partial^{2} w}{\partial \alpha^{2}}+\mu \frac{\partial^{2} w}{\partial \beta^{2}}\right)=0$,

$T_{\alpha}^{0}=c_{\alpha} \Delta_{\alpha}, T_{\alpha \beta}^{0}=0$

for $\beta=0, \beta=b$

$w=0, \quad M_{\beta}=-D\left(\frac{\partial^{2} w}{\partial \beta^{2}}+\mu \frac{\partial^{2} w}{\partial \alpha^{2}}\right)=0$,

$T_{\beta}^{0}=c_{\beta} \Delta_{\beta}, T_{\beta \alpha}^{0}=0$.

where $T_{\alpha}^{0}, T_{\beta}^{0}, T_{\alpha \beta}^{0}$ are the average values of the force at the edges of the plate, $\Delta_{\alpha}, \Delta_{\beta}$ are average relative declinations of edges, and $c_{\alpha}, C_{\beta}$-stiffness coefficients of elastic ties. If $C_{\alpha}, C_{\beta}$ are equal to zero, then we deal with a boundary value problem when the edge of the plate can freely move in own plane, and when $c_{\alpha}, c_{\beta}$ - are non-zero, then we have a problem when the edges of the plate are fixed.

\section{Solution of stability problem.}

An approximate solution of the formulated problem let's present using Galerkin method. Substituting it into the stability equations one can obtain a linear non-homogeneous differential equation with respect to the function $F$. By satisfying the boundary conditions one can obtain the following expression for $F$ :

$$
\begin{aligned}
F(\alpha, \beta, t) & =\frac{E h}{4}\left[-\frac{\mu_{1}^{2}}{\lambda_{1}^{2}} f_{1} f_{2} \cos \left(\lambda_{1} \alpha\right)+\frac{\mu_{1}^{2}}{8 \lambda_{1}^{2}} f_{1}^{2} \cos \left(\lambda_{2} \alpha\right)+\frac{\mu_{1}^{2}}{9 \lambda_{1}^{2}} f_{1} f_{2} \cos \left(\lambda_{3} \alpha\right)+\right. \\
+ & \frac{\mu_{1}^{2}}{32 \lambda_{1}^{2}} f_{2}^{2} \cos \left(\lambda_{4} \alpha\right)+\frac{9 \lambda_{1}^{2} \mu_{1}^{2}}{\Delta_{\lambda_{1} \mu_{2}}} f_{1} f_{2} \cos \left(\lambda_{1} \alpha\right) \cos \left(\mu_{2} \beta\right)- \\
& \left.-\frac{\lambda_{1}^{2} \mu_{1}^{2}}{\Delta_{\lambda_{3} \mu_{2}}} f_{1} f_{2} \cos \left(\lambda_{3} \alpha\right) \cos \left(\mu_{2} \beta\right)+\left(\frac{\lambda_{1}^{2}}{2 \mu_{1}^{2}} f_{2}^{2}+\frac{\lambda_{1}^{2}}{8 \mu_{1}^{2}} f_{1}^{2}\right) \cos \left(\mu_{2} \beta\right)\right]- \\
+ & \frac{1}{2}\left(T_{\alpha}^{0} \beta^{2}+T_{\beta}^{0} \alpha^{2}\right)
\end{aligned}
$$

where

$T_{\alpha}^{0}=\frac{\pi^{2} E h \delta_{1}}{8 a^{2}\left(1-\mu^{2} \delta_{1} \delta_{2}\right)}\left(f_{1}^{2}+4 f_{2}^{2}+\mu \varphi^{2} \delta_{2}\left(f_{1}^{2}+f_{2}^{2}\right)\right)$,

$T_{\beta}^{0}=\frac{\pi^{2} E h \delta_{2}}{8 a^{2}\left(1-\mu^{2} \delta_{1} \delta_{2}\right)}\left(\varphi^{2}\left(f_{1}^{2}+4 f_{2}^{2}\right)+\mu \delta_{1}\left(f_{1}^{2}+4 f_{2}^{2}\right)\right), \quad \varphi=\frac{a}{b}$

Here the following notations are done: 
$\delta_{1}=\left(1+\frac{E h}{a c_{\alpha}}\right)^{-1}, \delta_{2}=\left(1+\frac{E h}{b c_{\beta}}\right)^{-1}$. The values $\delta_{1}=0, \quad \delta_{2}=0 \quad$ correspond to the conditions of free in the plane edges, non-zero values correspond to the fixed edges, and values $\delta_{1}=1, \quad \delta_{2}=1$ correspond to the conditions of fixed in the plane edges.

To determine the unknown functions $f_{i k}(t)$ let's substitute the solution of Galerkin's form into the stability equations and using the Bubnov-Galerkin method, with respect to the to dimensionless functions $x_{1}=f_{1}(t) / h, x_{2}=f_{2}(t) / h$ the following nonlinear system of ordinary differential equations is obtained [3]:

$$
\begin{aligned}
& \frac{d^{2} x_{1}}{d \tau^{2}}+\chi \frac{d x_{1}}{d \tau}+x_{1}-\frac{2}{3} k v x_{2}+k v^{2}\left[\alpha_{11} x_{1}^{2}+\alpha_{12} x_{2}^{2}+\right. \\
& \left.+v x_{2}\left(\beta_{11} x_{1}^{2}+\beta_{12} x_{2}^{2}\right)\right]+Q x_{1}\left(\gamma_{11} x_{1}^{2}+\gamma_{12} x_{2}^{2}\right)=0 \\
& \frac{d^{2} x_{2}}{d \tau^{2}}+\chi \frac{d x_{2}}{d \tau}+\gamma^{2} x_{2}+\frac{2}{3} k v x_{1}+k v^{2}\left[\alpha_{21} x_{1} x_{2}+\right. \\
& \left.+v x_{1}\left(\beta_{21} x_{1}^{2}+\beta_{22} x_{2}^{2}\right)\right]+Q x_{2}\left(\gamma_{21} x_{1}^{2}+\gamma_{22} x_{2}^{2}\right)=0 .
\end{aligned}
$$

Herein, along with the dimensionless time $\tau=\omega_{1} t$, the following notations are done:

$$
\begin{aligned}
& \omega_{i}^{2}=\frac{D}{\rho_{0} h}\left(\lambda_{i}^{2}+\mu_{1}^{2}\right)^{2} \quad(i=1,2), \quad k=\frac{4 æ p_{\infty}}{\rho_{0} \omega_{1}^{2} h^{2}}, \quad Q=\frac{h}{16 \rho_{0} \omega_{1}^{2}}, \\
& v=M \frac{h}{a}, \quad \gamma=\frac{\omega_{2}}{\omega_{1}}, \quad \chi=\frac{2}{\omega_{1}}\left(\varepsilon+\frac{æ p_{\infty}}{\rho_{0} h a_{\infty}}\right) \\
& \alpha_{11}=\frac{2}{9}(\mathfrak{x}+1), \quad \alpha_{12}=\frac{56}{45}(\mathfrak{x}+1), \quad \alpha_{21}=\frac{16}{45}(\mathfrak{x}+1), \beta_{11}=\beta_{21}=\frac{\pi^{2}}{40}(\mathfrak{x}+1), \\
& \beta_{22}=\frac{11 \pi^{2}}{70}(\mathfrak{x}+1), \quad \beta_{12}=-\frac{9 \pi^{2}}{70}(\mathfrak{x}+1), \gamma_{11}=E h \lambda_{1}^{4}\left(1+\varphi^{4}+2 \frac{\left(\delta_{1}+2 \mu \varphi^{2} \delta_{1} \delta_{2}+\varphi^{4} \delta_{2}\right)}{1-\mu^{2} \delta_{1} \delta_{2}}\right) \text {, } \\
& \gamma_{12}=\gamma_{21}=E h \lambda_{1}^{4}\left(4\left(1+\varphi^{4}\right)+\frac{81 \varphi^{4}}{\left(1+4 \varphi^{2}\right)^{2}}+\frac{\varphi^{4}}{\left(9+4 \varphi^{2}\right)^{2}}+2 \frac{\left(4 \delta_{1}+5 \mu \varphi^{2} \delta_{1} \delta_{2}+\varphi^{4} \delta_{2}\right)}{1-\mu^{2} \delta_{1} \delta_{2}}\right) \text {, } \\
& \gamma_{22}=\operatorname{Eh} \lambda_{1}^{4}\left(16+\varphi^{4}+2 \frac{\left(16 \delta_{1}+8 \mu \varphi^{2} \delta_{1} \delta_{2}+\varphi^{4} \delta_{2}\right)}{1-\mu^{2} \delta_{1} \delta_{2}}\right) \text {, }
\end{aligned}
$$

where $\omega_{1}$ and $\omega_{2}$ - are first and second natural frequencies of the plate, while $v$ is the reduced speed parameter.

The solution of the nonlinear problem is usually preceded by analysis of the corresponding linear problem, which is done in detail in the work [6] and accordingly, the critical flutter speed in the case of the selected buckling form of the plate is obtained. After the nonlinear 
problem is solved using harmonic balace method. As a result the system of non-linear algebraic equations are obtained [6].

\section{Character of the dependence «amplitude-frequency» at critical speeds, when the edges of the plate have identical fixing conditions}

Brought in $[4,5]$ numerical investigations show that the relation $h / a$ has essential influence (both qualitative and quantitative) on the character of the dependence «amplitudefrequency». That is why the cases of both relatively thick and sufficiently thin plates will be investigated here separately.

Case 1. Thick plates $\left(\mathbf{h} / \mathbf{a}>10^{-2}\right)$. The results of numerical solution of the system (15) from the work [6] for $v=v_{c r}$ and several boundary conditions are brought in the Table 1. Calculated values of the amplitude of oscillations are brought here for $a=70 h$ and for several fixed $b / a$.

Table 1. Dependence "amplitude-frequency, $A(\theta)$ for $\mathbf{h} / \mathbf{a}=\mathbf{1} / \mathbf{7 0}$, several $\mathbf{b} / \mathbf{a}$

\begin{tabular}{|c|c|c|c|c|c|c|c|c|c|c|c|}
\hline & \multicolumn{10}{|c|}{$\mathrm{b} / \mathrm{a}=3$} \\
\hline$\delta_{i} \theta$ & 0 & $\begin{array}{l}\hat{6} \\
\tilde{0} \\
0\end{array}$ & $\stackrel{\nabla}{-}$ & $\stackrel{?}{\stackrel{2}{*}}$ & $N$ & $\vec{i}$ & & $\stackrel{\infty}{i}$ & ָे & $\nabla$ & $\begin{array}{l}\infty \\
\text { Ș } m \\
\text { in }\end{array}$ \\
\hline $\begin{array}{l}\delta_{1}=0 \\
\delta_{2}=0\end{array}$ & 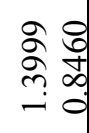 & 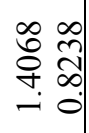 & 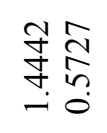 & 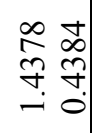 & 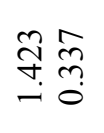 & $\stackrel{0}{m}$ & & 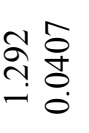 & 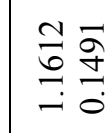 & $\begin{array}{l}\stackrel{0}{n} \\
\stackrel{n}{n} \\
\stackrel{n}{0} \\
0\end{array}$ & \\
\hline $\begin{array}{l}\delta_{1}=0.25 \\
\delta_{2}=0.25\end{array}$ & & $\stackrel{0}{\circ}$ & \begin{tabular}{c}
\multirow{f}{*}{$\tilde{b}$} \\
$-i$ \\
-0
\end{tabular} & 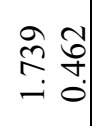 & 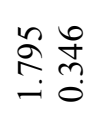 & $\stackrel{\infty}{\sigma}$ & & 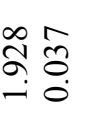 & 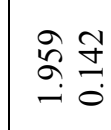 & 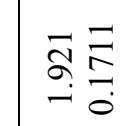 & 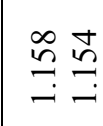 \\
\hline $\begin{array}{l}\delta_{1}=1 \\
\delta_{2}=1\end{array}$ & & & ' & $\begin{array}{cc}0 & \hat{n} \\
0 & 0 \\
\infty & 0 \\
0 & 0\end{array}$ & 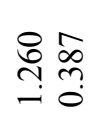 & ڤ̊ & & 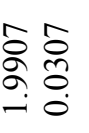 & 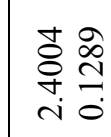 & 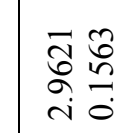 & 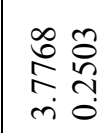 \\
\hline \multicolumn{12}{|c|}{$\mathrm{b} / \mathrm{a}=2$} \\
\hline & 0 & $\stackrel{\nabla}{-}$ & הֶ. & $N$ & $\begin{array}{l}\text { : } \\
\text { in } \\
\text { in }\end{array}$ & & $\begin{array}{l}\infty \\
i\end{array}$ & & $\ddot{n}$ & $\begin{array}{l}\tilde{O} \\
0 \\
\dot{0} \\
\dot{n}\end{array}$ & $\sigma$ \\
\hline $\begin{array}{l}\delta_{1}=0 \\
\delta_{2}=0\end{array}$ & 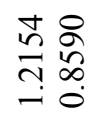 & 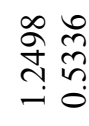 & 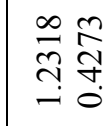 & 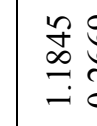 & $\begin{array}{l}\tilde{n} \\
\tilde{o} \\
-\end{array}$ & & $\begin{array}{ll}\Delta & \hat{n} \\
\hat{n} & \stackrel{2}{0} \\
\hat{0} & 0\end{array}$ & & 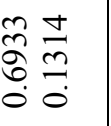 & 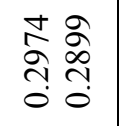 & ' \\
\hline $\begin{array}{l}\delta_{1}=1 \\
\delta_{2}=1\end{array}$ & & ' & 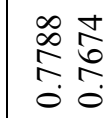 & 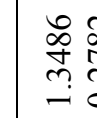 & $\stackrel{\infty}{\stackrel{\infty}{\infty}}$ & & 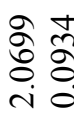 & & 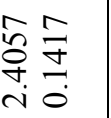 & 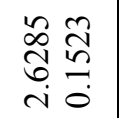 & 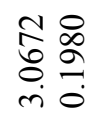 \\
\hline
\end{tabular}




\begin{tabular}{|c|c|c|c|c|c|c|c|c|c|c|c|}
\hline \multicolumn{12}{|c|}{$\mathrm{b} / \mathrm{a}=1.5$} \\
\hline & 0 & \multicolumn{2}{|l|}{$\stackrel{+}{-}$} & $\begin{array}{l}0 \\
\infty \\
0 \\
0 \\
\end{array}$ & $\sim$ & 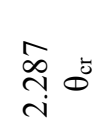 & $\tilde{i}$ & \multicolumn{2}{|c|}{$\begin{array}{l}\vec{\infty} \\
\stackrel{\sim}{i}\end{array}$} & $\ddot{n}$ & $\nabla$ \\
\hline $\begin{array}{l}\delta_{1}=0 \\
\delta_{2}=0\end{array}$ & 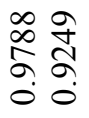 & \multicolumn{2}{|c|}{ 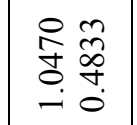 } & 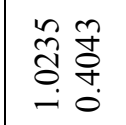 & 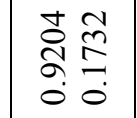 & 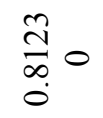 & $\begin{array}{l}\hat{n} \cong \\
\stackrel{0}{0}:\end{array}$ & \multicolumn{2}{|c|}{ 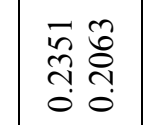 } & ' & I \\
\hline $\begin{array}{l}\delta_{1}=1 \\
\delta_{2}=1\end{array}$ & ' & 1 & \multicolumn{2}{|c|}{ 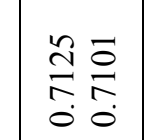 } & $\begin{array}{ll}0 & 0 \\
0 & 0 \\
& 0 \\
-1 & 0\end{array}$ & 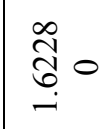 & 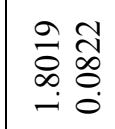 & \multicolumn{2}{|c|}{ 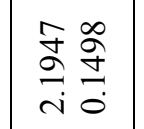 } & 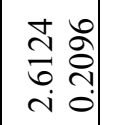 & 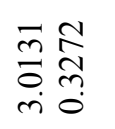 \\
\hline \multicolumn{12}{|c|}{$\mathrm{b} / \mathrm{a}=1.3$} \\
\hline & 0 & $\tilde{n}$ & $\begin{array}{l}\infty \\
0 \\
\infty \\
0\end{array}$ & - & $\begin{array}{l}\text { N } \\
\text { nุ. } \\
-\end{array}$ & $\stackrel{\infty}{-}$ & $\begin{array}{ll}\infty & 0 \\
\stackrel{0}{n} & 0 \\
\vec{i} & \end{array}$ & $\stackrel{\nabla}{i}$ & $\underset{\stackrel{d}{i}}{\stackrel{d}{d}}$ & $\begin{array}{l}\infty \\
\infty \\
\infty \\
\infty \\
i\end{array}$ & $\ddot{n}$ \\
\hline $\begin{array}{l}\delta_{1}=0 \\
\delta_{2}=0\end{array}$ & ' & 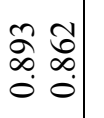 & $\begin{array}{lll}t & 0 \\
0 & 0 & 0 \\
0 & 0 \\
0 & 0\end{array}$ & $\begin{array}{ll}n & \overline{0} \\
\circ & 0 \\
0 & 0\end{array}$ & 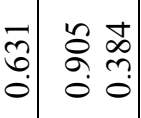 & 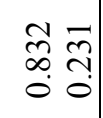 & $\begin{array}{ll}0 & 0 \\
0 & 0 \\
0 & 0\end{array}$ & 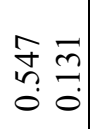 & \begin{tabular}{ll}
$\infty$ & $\sigma$ \\
\hdashline & $\sigma$ \\
0 & 0 \\
0
\end{tabular} & & \\
\hline $\begin{array}{l}\delta_{1}=0.25 \\
\delta_{2}=0.25\end{array}$ & ' & ' & $\begin{array}{cc}\infty & \tilde{2} \\
2 & 0 \\
0 & 0 \\
0 & 0\end{array}$ & $\stackrel{m}{0} \stackrel{\tilde{\imath}}{0}$ & 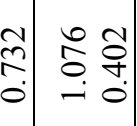 & 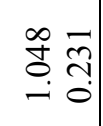 & ڤू̆ & 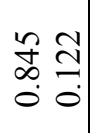 & 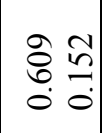 & $\begin{array}{ll}0 & 0 \\
0 & 8 \\
0 & 0 \\
0 & 0\end{array}$ & ? \\
\hline $\begin{array}{l}\delta_{1}=1 \\
\delta_{2}=1\end{array}$ & ' & ' & ' & ' & $\begin{array}{ll}t & 0 \\
0 & 0 \\
0 & 0 \\
0 & 0\end{array}$ & 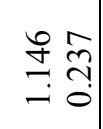 & 号o & 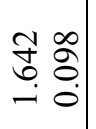 & 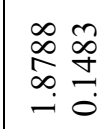 & 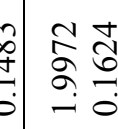 & 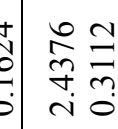 \\
\hline \multicolumn{12}{|c|}{$\mathrm{b} / \mathrm{a}=1$} \\
\hline & 0 & $\begin{array}{l}\infty \\
\stackrel{\infty}{\infty} \\
\vdots \\
0\end{array}$ & & 导 & $\stackrel{\infty}{-}$ & के & $\vec{i}$ & $\underset{\sim}{\stackrel{ \pm}{i}}$ & $\begin{array}{l}t \\
j \\
v\end{array}$ & $\begin{array}{l}\widehat{\sigma} \\
\stackrel{0}{0} \\
\text { i }\end{array}$ & $\ddot{n}$ \\
\hline $\begin{array}{l}\delta_{1}=0 \\
\delta_{2}=0\end{array}$ & ' & $\underset{ }{ } \stackrel{2}{\stackrel{2}{ }}$ & & 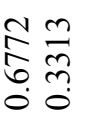 & $\begin{array}{ll}n & 8 \\
& 8 \\
& 0 \\
0 & 0\end{array}$ & $\stackrel{n}{\stackrel{n}{f}} 0$ & 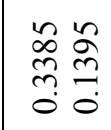 & $\begin{array}{l}2 \\
\infty \\
0 \\
0\end{array}$ & 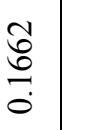 & 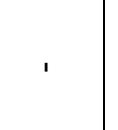 & ' \\
\hline $\begin{array}{l}\delta_{1}=1 \\
\delta_{2}=1\end{array}$ & ' & ' & & $\begin{array}{ll}\infty & 0 \\
n & o \\
n & \vdots \\
n & n \\
0 & 0\end{array}$ & $\begin{array}{ll}\hat{o} & \frac{1}{0} \\
\hat{o} & 0 \\
0 & 0\end{array}$ & 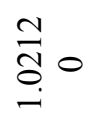 & 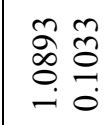 & $\begin{array}{l} \pm: \\
\Xi \\
\Xi\end{array}$ & $\frac{\tilde{F}}{\frac{7}{0}}$ & 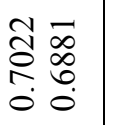 & ' \\
\hline
\end{tabular}




\begin{tabular}{|c|c|c|c|c|c|c|c|c|c|}
\hline \multicolumn{10}{|c|}{$\mathrm{b} / \mathrm{a}=0.6$} \\
\hline$\delta_{i}{ }^{\theta}$ & 0 & $\begin{array}{l}\text { ָै } \\
\text { ָ̦ }\end{array}$ & $\begin{array}{l}\hat{\mathrm{o}} \\
\stackrel{2}{-}\end{array}$ & $\stackrel{\nabla}{+}$ & 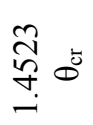 & $\stackrel{8}{\stackrel{0}{.}}$ & 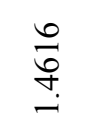 & 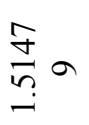 & $\stackrel{-}{\circ}$ \\
\hline $\begin{array}{l}\delta_{1}=0 \\
\delta_{2}=0\end{array}$ & ' & 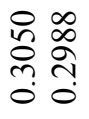 & 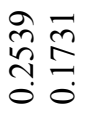 & 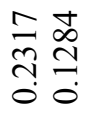 & $\begin{array}{l}\stackrel{t}{0} \\
\stackrel{0}{0} \\
0\end{array}$ & $\begin{array}{l}\hat{n}= \\
\stackrel{2}{0} \\
0\end{array}$ & 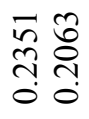 & ' & ' \\
\hline $\begin{array}{l}\delta_{1}=1 \\
\delta_{2}=1\end{array}$ & ' & & 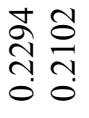 & 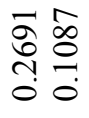 & $\begin{array}{l}\hat{n} \\
\text { तै } \\
\text { o }\end{array}$ & 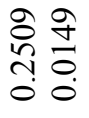 & 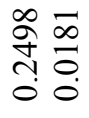 & 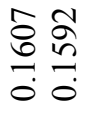 & 1 \\
\hline
\end{tabular}

In Table 1 the symbol "-" means that the amplitude of oscillation for the specific parameter set is equals to zero and there are no periodic solutions of the system (15) of the work [6]. Figure 1 is plotted on the basis if the Table 1.

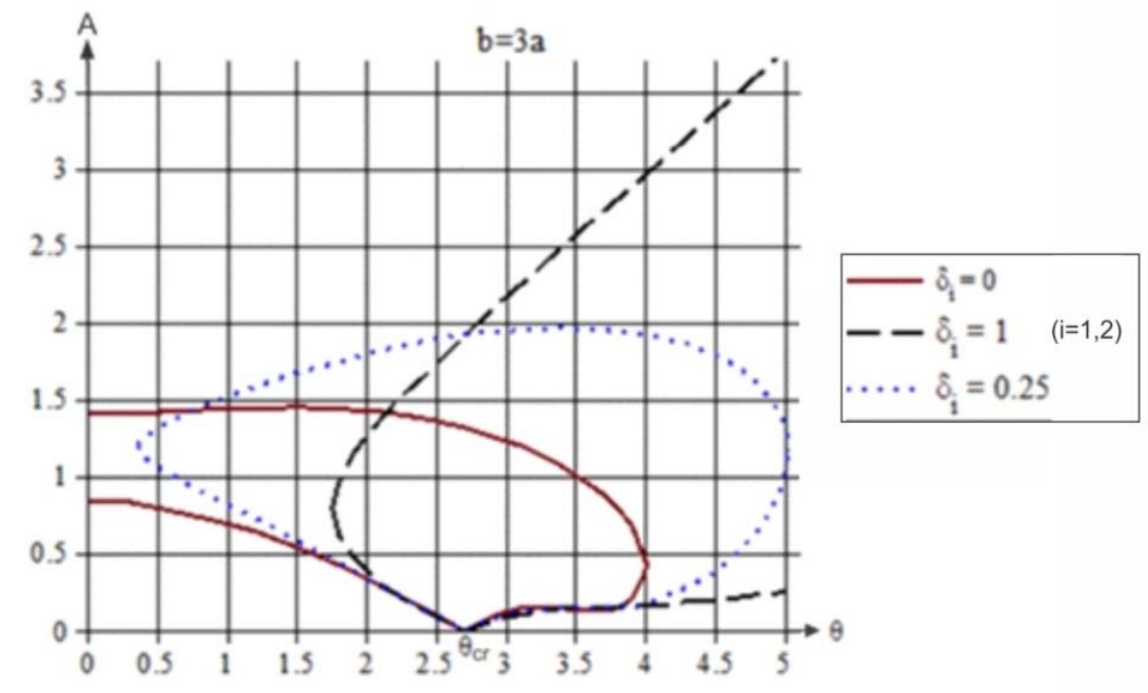

a)

Tabe 1 and Fig. 1 show, that:

- for $b / a>1$ if $\delta_{i}=0(i=1,2)$ there is a range $\left[\theta_{*}, \theta^{*}\right]$ of frequency $\theta$, where the function $A(\theta)$ is a two-value, and out of which the steady nonlinear flutter type oscillations cannot be obtained (for great values of the relation $b / a$ one can obtain $\left.\theta_{*} \approx 0\right)$. Uniform increase of values $\delta_{i}(i=1,2)$ brings to the increase of the values $\theta_{*}$. If $\delta_{i}=1(i=1,2)$, then the interval $\left[\theta_{*}, \infty\right)$ exists, where the function $A(\theta)$ is a two-valued; 
- for $0.5<\frac{b}{a} \leq 1$ regardless of the character of boundary conditions there exists a finite interval $\theta_{*} \leq \theta \leq \theta^{*}$ at which nonlinear oscillations are possible. Moreover, change of boundary conditions causes the change of location and length of the noted interval;

- for sufficiently small values of the parameter $b / a$ the length of the interval of frequency change $\theta$ decreases and tents to zero independently of boundary conditions (there is impossible to generate nonlinear flutter type oscillations);

- with the increase of the parameter $\delta_{i}(i=1,2)$ from zero to unit the tightening of the amplitude (for $b / a>1$ ) switches from the high-frequency in the direction of lower frequencies.

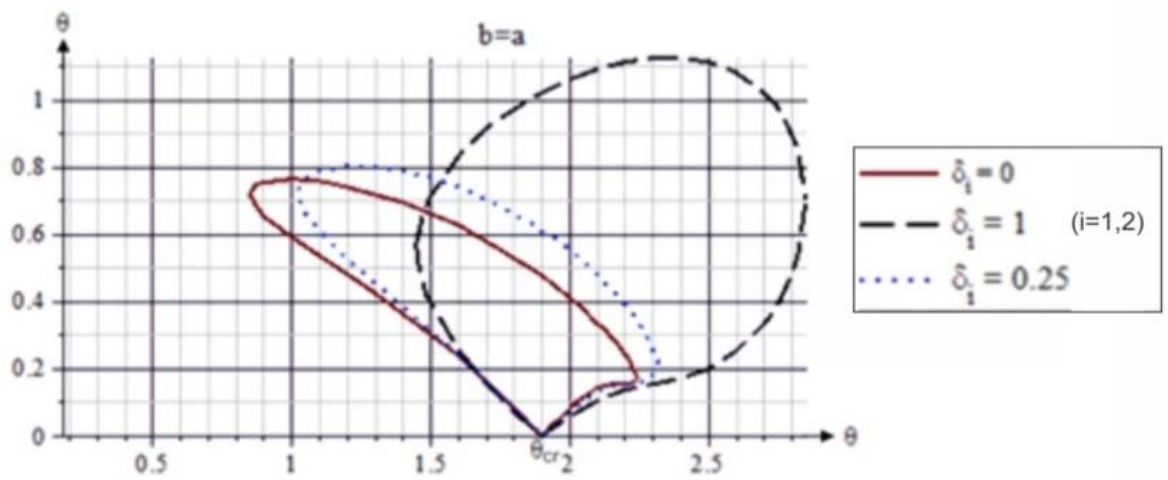

b)

Fig.1 Dependence «amplitude-frequency», for $a=70 h$ and several fixing conditions.

Case 2. Sufficiently thin plates $\left(\mathbf{h} / \mathbf{a}<\mathbf{1 0}^{-2}\right)$. In this case, also, numerical calculations are done for several values of the parameter $b / a$ and for several boundary conditions when $h / a$ is fixed. In particular, in the Table 2 the values of the amplitude are brought, when $a=120 h$. 
Table 2. Dependence «amplitude-frequency», $A(\theta)$ for $\mathbf{h} / \mathbf{a}=\mathbf{1 / 1 2 0}$, several $\mathbf{b} / \mathbf{a}$ and fixing conditions

\begin{tabular}{|c|c|c|c|c|c|c|c|c|c|}
\hline \multicolumn{10}{|c|}{$\mathrm{b} / \mathrm{a}=3$} \\
\hline & 0 & $\frac{N}{N}$ & 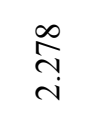 & $\begin{array}{l}\text { å } \\
\text { ஸे } \\
\text { ci }\end{array}$ & $\stackrel{n}{\sim}$ & $\frac{\overrightarrow{0}}{i} 0^{\circ}$ & $n$ & $n$ & $\nabla$ \\
\hline $\begin{array}{l}\delta_{1}=0 \\
\delta_{2}=0\end{array}$ & 1 & 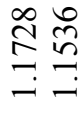 & 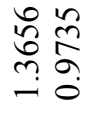 & 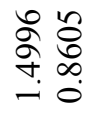 & 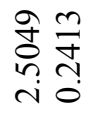 & $\stackrel{\stackrel{0}{ \pm}}{\stackrel{m}{m}}$ & 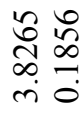 & 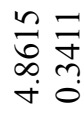 & 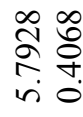 \\
\hline $\begin{array}{l}\delta_{1}=0.25 \\
\delta_{2}=0.25\end{array}$ & 1 & ' & 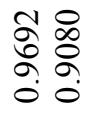 & 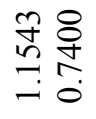 & 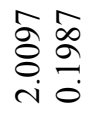 & 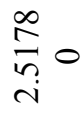 & 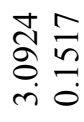 & 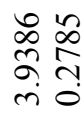 & $\begin{array}{l}\tilde{n} \\
\hat{\sigma} \tilde{m} \\
\dot{+} \tilde{0}\end{array}$ \\
\hline $\begin{array}{l}\delta_{1}=1 \\
\delta_{2}=1\end{array}$ & 1 & 1 & 1 & 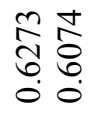 & 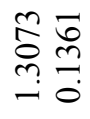 & 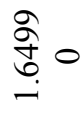 & 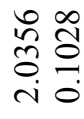 & 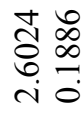 & 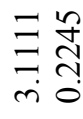 \\
\hline \multicolumn{10}{|c|}{$\mathrm{b} / \mathrm{a}=1$} \\
\hline & 0 & $\stackrel{+}{\hat{\sigma}}$ & 공 & 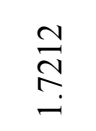 & $\stackrel{\infty}{-}$ & غे ڤ్ & $\stackrel{n}{\sim}$ & $m$ & $\nabla$ \\
\hline $\begin{array}{l}\delta_{1}=0 \\
\delta_{2}=0\end{array}$ & ' & 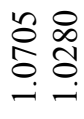 & 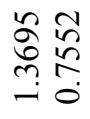 & 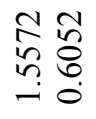 & 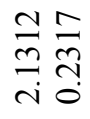 & $\begin{array}{l}\circ \\
\stackrel{8}{0} 0 \\
\text { i }\end{array}$ & 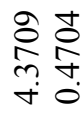 & 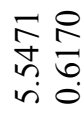 & 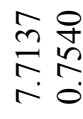 \\
\hline $\begin{array}{l}\delta_{1}=0.25 \\
\delta_{2}=0.25\end{array}$ & ' & ' & 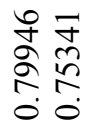 & 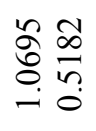 & 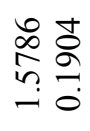 & 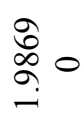 & 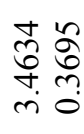 & 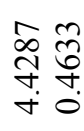 & 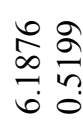 \\
\hline $\begin{array}{l}\delta_{1}=1 \\
\delta_{2}=1\end{array}$ & ' & ' & ' & $\begin{array}{l}9 \\
\text { ô } \\
0 \\
\dot{f} \\
\dot{f} \\
0\end{array}$ & \begin{tabular}{l}
$a$ \\
\multirow{2}{N}{$\cong$} \\
$\infty$ \\
0 \\
0
\end{tabular} & $\begin{array}{l}n \\
\infty \\
\stackrel{n}{=}\end{array}$ & 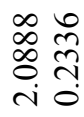 & 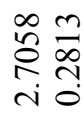 & 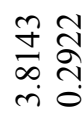 \\
\hline \multicolumn{10}{|c|}{$\mathrm{b} / \mathrm{a}=0.6$} \\
\hline & 0 & ลે & $\stackrel{+}{\sim}$ & \&. & $\underset{\sim}{\stackrel{\sim}{\sim}} 0^{\dot{0}}$ & $m$ & $\nabla$ & $n$ & $r$ \\
\hline $\begin{array}{l}\delta_{1}=0 \\
\delta_{2}=0\end{array}$ & ' & 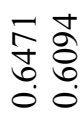 & 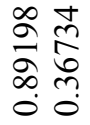 & 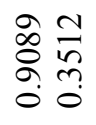 & $\begin{array}{l}\hat{n} \\
\tilde{n}\end{array}$ & 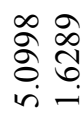 & 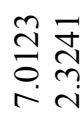 & 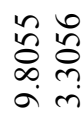 & 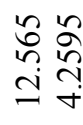 \\
\hline
\end{tabular}




\begin{tabular}{|c|c|c|c|c|c|c|c|c|c|}
\hline $\begin{array}{l}\delta_{1}=0.25 \\
\delta_{2}=0.25\end{array}$ & ' & ' & 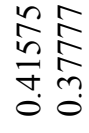 & \begin{tabular}{ll}
$n$ & 0 \\
$\infty$ & $\infty$ \\
0 & $\mathbb{1}$ \\
\multirow{1}{*}{} & $?$ \\
0 & 0
\end{tabular} & 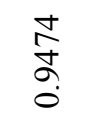 & 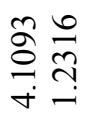 & 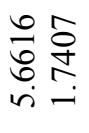 & 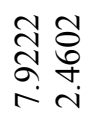 & $\begin{array}{l}\stackrel{\infty}{n} \tilde{\hat{C}} \\
\stackrel{n}{0} \\
\dot{0} \\
\dot{0}\end{array}$ \\
\hline $\begin{array}{l}\delta_{1}=1 \\
\delta_{2}=1\end{array}$ & ' & ' & & 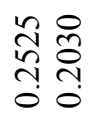 & $\begin{array}{l}\infty \\
\stackrel{n}{n} \\
0\end{array}$ & 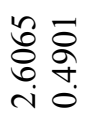 & 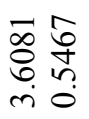 & $\begin{array}{ll}N & \bar{n} \\
n & \infty \\
0 & n \\
n & 0\end{array}$ & 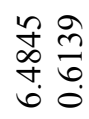 \\
\hline
\end{tabular}

On the basis of the Table 2 the Fig. 2 is plotted.

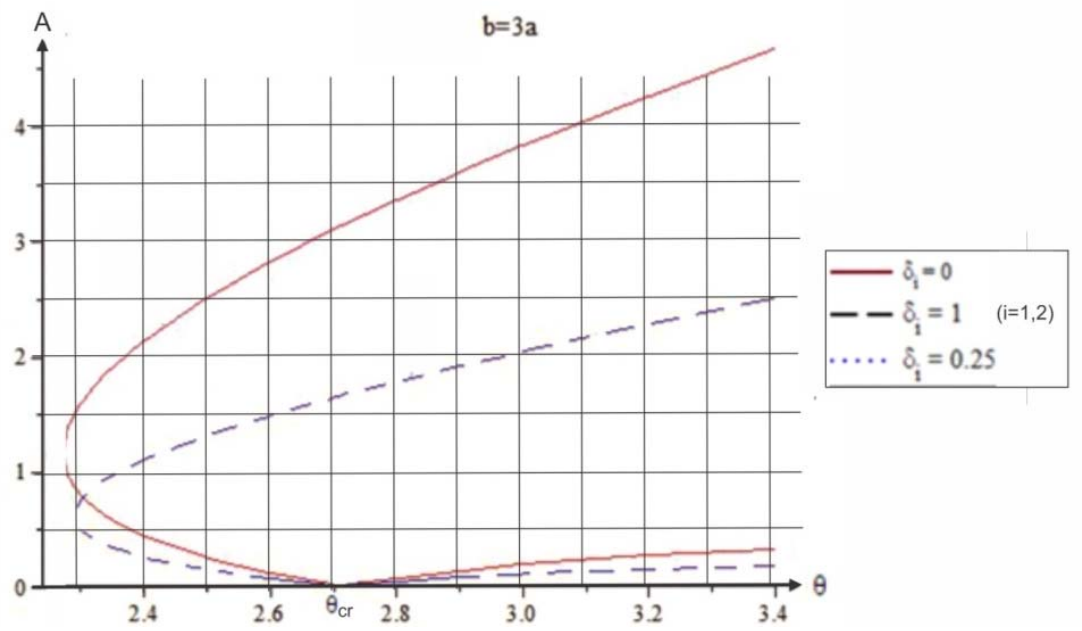

Fig.2. Dependence "amplitude-frequency", for $a=120 \mathrm{~h}$ and several fixing conditions

Table 2 and Fig. 2 show, that for the examined case when $b / a>0.78$, then independently of boundary conditions the following character of the function $A(\theta)$ takes place: there is a such certain value $\theta_{*}\left(\theta_{*}<\theta_{c r}\right)$ exists, that it is possible to generate flutter type oscillations only in the interval $\left[\theta_{*}, \infty\right)$. The value $\theta_{*}$ increases with both increase of $\mathrm{b} / \mathrm{a}$, and decrease of $\mathrm{h} / \mathrm{a}$. The influence of boundary condition on the character of the function $A(\theta)$ is quantitative only. During the transition from the free edges to the case of fixed edges the amplitude decreases.

Let's note, also, that if $b / a<0.78$, then the qualitative change of the character of the dependence «amplitude-frequency» is possible during the transition from one type boundary conditions to another (for a fairly thin plates). 
Thus, in the case of the problem with the fixed in the plane edges only two cases of the dependence "amplitude-frequency" are possible (the dotted lines in the Figures 1 and 2). Moreover, the transition from one type to another happens only due to the change of the relation $b / a$. In the case of the problem with free in the plane edges the three cases of the dependence «amplitude-frequency» are possible (solid lines in the Figures 1 and 2).

\section{Character of the dependence "amplitude-frequency" for the mixed boundary conditions}

So far we examined the cases when the edges of the plate were similarly fixed. Let's study now the cases, when at the adjacent edges of simply supported plate the different boundary conditions in plane direction are addressed. The condition $\delta_{1}=0, \delta_{2}=1$ means, that the edges of the plate are free in the plane along the axis $O \alpha$, and are fixed in own plane along the axis $O \beta$. Similarly, the condition $\delta_{1}=1, \delta_{2}=0$ means, edges of the plate are fixed in own plane along the axis $O \alpha$, and are free in the plane along the axis $O \beta$. The results of numerical simulations are brought in the Table 3 for thick $\left(h / a>10^{-2}\right)$ and in the Table 4 for thin $\left(h / a<10^{-2}\right)$ plates for several values of the relation $b / a$ and several mixed boundary conditions.

Table 3. Influence of mixed boundary conditions on the dependence $A(\theta)$ for $\mathbf{h} / \mathbf{a}=\mathbf{1 / 7 0}$

\begin{tabular}{|c|c|c|c|c|c|c|c|c|c|c|}
\hline \multicolumn{11}{|c|}{$\mathrm{b} / \mathrm{a}=3$} \\
\hline & 0 & - & 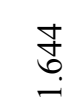 & $\stackrel{0}{\stackrel{2}{*}}$ & $N$ & $\vec{i}{ }^{\circ}$ & $\stackrel{\infty}{i}$ & $\stackrel{\sim}{n}$ & ナ & $n$ \\
\hline $\begin{array}{l}\delta_{1}=0 \\
\delta_{2}=0\end{array}$ & 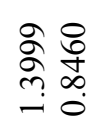 & 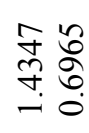 & 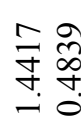 & 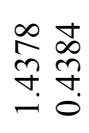 & $\begin{array}{c}\tilde{丶} \\
\stackrel{m}{0}\end{array}$ & $\stackrel{\vec{m}}{\underline{m}} 0$ & 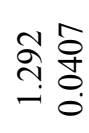 & $\begin{array}{l}\stackrel{ }{\sigma} \bar{g} \\
\stackrel{-}{-}\end{array}$ & 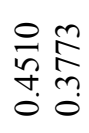 & ' \\
\hline $\begin{array}{l}\delta_{1}=0 \\
\delta_{2}=1\end{array}$ & 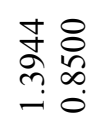 & $\begin{array}{l}=8 \\
\vec{\sigma} \\
\stackrel{8}{0} \\
\stackrel{0}{0}\end{array}$ & $\begin{array}{l}\hat{\sigma} \\
\text { fे } \\
\stackrel{f}{-}\end{array}$ & 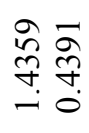 & 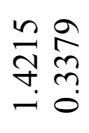 & 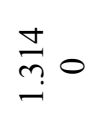 & 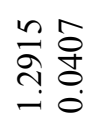 & 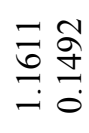 & 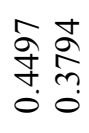 & \\
\hline $\begin{array}{l}\delta_{1}=1 \\
\delta_{2}=1\end{array}$ & ' & ' & ' & $\begin{array}{ll}0 & \tilde{n} \\
0 & 0 \\
0 & 0\end{array}$ & 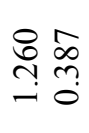 & S̊ & 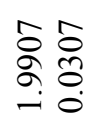 & 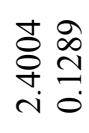 & 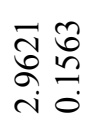 & 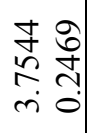 \\
\hline $\begin{array}{l}\delta_{1}=1 \\
\delta_{2}=0\end{array}$ & ' & 1 & 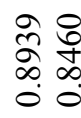 & 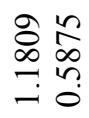 & 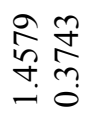 & $\underset{\hat{\sigma}}{\stackrel{0}{0}}$ & 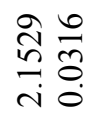 & $\begin{array}{l}\infty \\
\stackrel{\infty}{0} \\
\underset{+}{*} \\
i \\
\sim\end{array}$ & 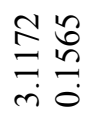 & 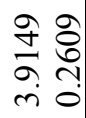 \\
\hline
\end{tabular}




\begin{tabular}{|c|c|c|c|c|c|c|c|c|c|c|}
\hline \multicolumn{11}{|c|}{$\mathrm{b} / \mathrm{a}=0.9$} \\
\hline$\theta$ & 0 & $\hat{a}$ & 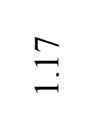 & $\stackrel{\infty}{=}$ & $\stackrel{\text { 巳 }}{-}$ & $\vec{D}_{\substack{\infty\\
}}$ & $\begin{array}{l}\hat{n} \\
\hat{\sigma} \\
i\end{array}$ & $\begin{array}{l}0 \\
\qquad \\
i \\
i\end{array}$ & 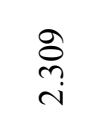 & $\hat{\grave{j}}$ \\
\hline $\begin{array}{l}\delta_{1}=0 \\
\delta_{2}=0\end{array}$ & ' & 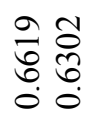 & 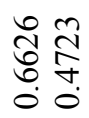 & $\begin{array}{ll}8 & \overline{0} \\
0 & 0 \\
0 & 0 \\
0 & 0\end{array}$ & 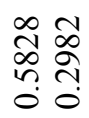 & \begin{tabular}{l} 
to \\
\multirow{+}{0}{0} \\
0
\end{tabular} & $\begin{array}{l}\cong \\
\infty \\
0 \\
0 \\
0\end{array}$ & $\begin{array}{l}\dot{J} \tilde{0} \\
\stackrel{0}{0} \\
\overrightarrow{0}\end{array}$ & ' & I \\
\hline $\begin{array}{l}\delta_{1}=0 \\
\delta_{2}=1\end{array}$ & ' & ' & ' & 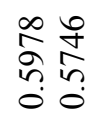 & 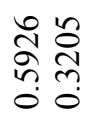 & 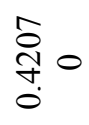 & $\frac{2}{0} \frac{\infty}{0}$ & ' & ' & ' \\
\hline $\begin{array}{l}\delta_{1}=1 \\
\delta_{2}=0\end{array}$ & ' & ' & 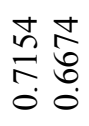 & 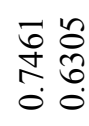 & 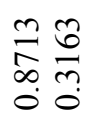 & $\begin{array}{l}\infty \\
\stackrel{1}{1} \\
\infty \\
0 \\
0\end{array}$ & 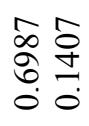 & 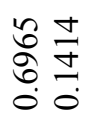 & $\begin{array}{l}\hat{\tilde{n}} \\
\tilde{N} \\
\tilde{0} \\
0\end{array}$ & ' \\
\hline $\begin{array}{l}\delta_{1}=1 \\
\delta_{2}=1\end{array}$ & ' & ' & I & ' & $\begin{array}{l}\tilde{W} \\
\vec{n} \\
\stackrel{m}{f} \\
\stackrel{0}{0}\end{array}$ & 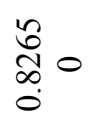 & 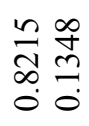 & $\begin{array}{l}\infty \\
\stackrel{n}{0} \\
\infty \\
0 \\
0 \\
0\end{array}$ & 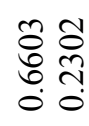 & 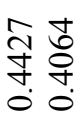 \\
\hline
\end{tabular}

Table 4. Influence of mixed boundary conditions on the dependence $A(\theta)$ for $\mathbf{h} / \mathbf{a}=\mathbf{1} / \mathbf{1 2 0}$

\begin{tabular}{|c|c|c|c|c|c|c|c|c|c|}
\hline \multicolumn{10}{|c|}{$\mathrm{b} / \mathrm{a}=3$} \\
\hline 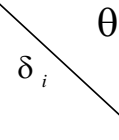 & 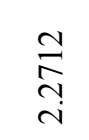 & 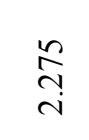 & 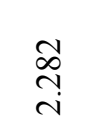 & $\begin{array}{l}\widetilde{\alpha} \\
\text { ָे } \\
\text { }\end{array}$ & $\tilde{n}$ & $\underset{i}{\stackrel{\sigma}{ }} 0^{\circ}$ & $m$ & $n$ & $\nabla$ \\
\hline $\begin{array}{l}\delta_{1}=0 \\
\delta_{2}=0\end{array}$ & 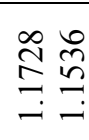 & 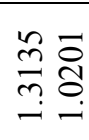 & 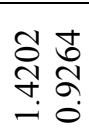 & 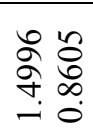 & 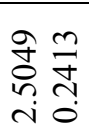 & 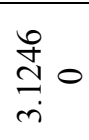 & 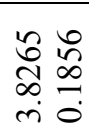 & 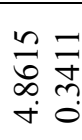 & 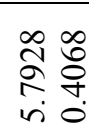 \\
\hline $\begin{array}{l}\delta_{1}=0 \\
\delta_{2}=1\end{array}$ & & 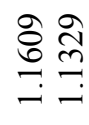 & 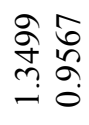 & 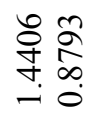 & 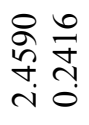 & 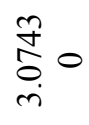 & 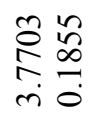 & 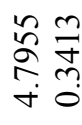 & 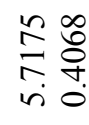 \\
\hline $\begin{array}{l}\delta_{1}=1 \\
\delta_{2}=1\end{array}$ & & & ' & 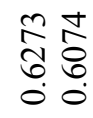 & 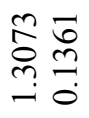 & $\stackrel{\text { gे }}{0} 0$ & 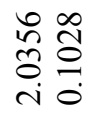 & 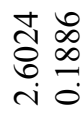 & 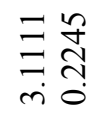 \\
\hline $\begin{array}{l}\delta_{1}=1 \\
\delta_{2}=0\end{array}$ & & & 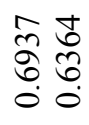 & 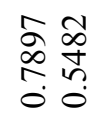 & 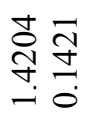 & 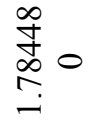 & $\begin{array}{l}\infty \\
2 \infty \\
\stackrel{0}{0} \\
\vec{i} \\
0\end{array}$ & $\begin{array}{ll}0 & 0 \\
0 & \stackrel{0}{\circ} \\
i & 0 \\
i & 0\end{array}$ & 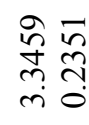 \\
\hline
\end{tabular}




\begin{tabular}{|c|c|c|c|c|c|c|c|c|c|c|}
\hline \multicolumn{11}{|c|}{$\mathrm{b} / \mathrm{a}=0.8$} \\
\hline & $\stackrel{\infty}{\sim}$ & $\stackrel{\infty}{n}$ & 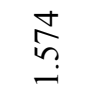 & $\stackrel{n}{\sigma}$ & ֶׁ. & 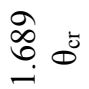 & $N$ & $\ddot{n}$ & $m$ & $\stackrel{n}{n}$ \\
\hline $\begin{array}{l}\delta_{1}=0 \\
\delta_{2}=0\end{array}$ & ' & 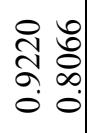 & 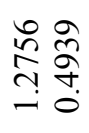 & 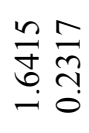 & 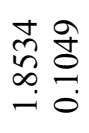 & $\begin{array}{l}\frac{n}{n} \\
\stackrel{n}{i} \\
i\end{array}$ & 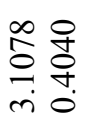 & 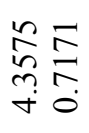 & 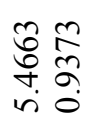 & 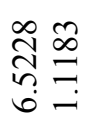 \\
\hline $\begin{array}{l}\delta_{1}=0 \\
\delta_{2}=1\end{array}$ & ' & & 1 & 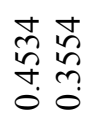 & 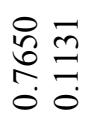 & 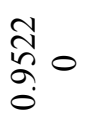 & 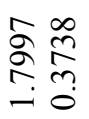 & 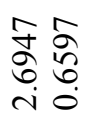 & \begin{tabular}{l}
$\hat{N}$ \\
\multirow{f}{*}{0} \\
$\dot{0}$ \\
$\dot{0} 0$
\end{tabular} & 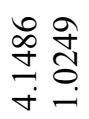 \\
\hline $\begin{array}{l}\delta_{1}=1 \\
\delta_{2}=0\end{array}$ & 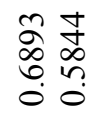 & 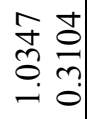 & 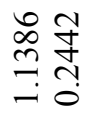 & 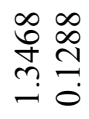 & 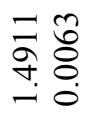 & 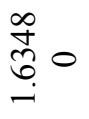 & 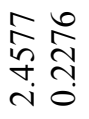 & 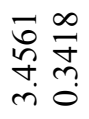 & 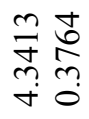 & 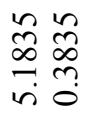 \\
\hline $\begin{array}{l}\delta_{1}=1 \\
\delta_{2}=1\end{array}$ & ' & & 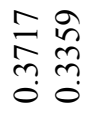 & 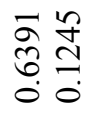 & 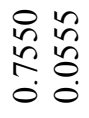 & $\begin{array}{l}\text { त्रे } \\
\infty \\
0 \\
0\end{array}$ & $\begin{array}{l}\stackrel{\vec{n}}{\hat{\sigma}} \\
\stackrel{2}{\circ}\end{array}$ & 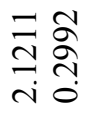 & 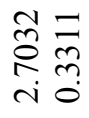 & 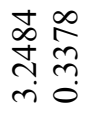 \\
\hline
\end{tabular}

Tables 3 and 4 show, that:

- if the plate is thick enough, and the ratio $b / a$ is greater than unit, then the solution of the problem with the boundary conditions $\delta_{1}=0, \delta_{2}=1$ as qualitatively, as well as quantitatively no different from the solution of the problem with the free edges in the plane, and the solution of the problem with the boundary conditions $\delta_{1}=1, \delta_{2}=0$ is similar to the solution of the problem with fixed in the plane edges. This fact also follows from the expressions for $\gamma_{i j}$. When the condition $\frac{b}{a} \leq 1$ is true, then the second case takes place independently of the boundary conditions (Fig.1(b)).

- If the plate is thin enough, this influence has only quantitative character. Moreover the value of the amplitudes obtained from the mixed boundary conditions is less than the corresponding values, obtained in the case of the free in the plane edges and is greater than the corresponding values in the case of fixed in own plane edges.

Mainly, if the ratio $b / a$ is greater than unit, the change of boundary conditions along the edges parallel to the direction of flowing stream have not essential influence on the dependence «amplitude-frequency» of plates. But the change of boundary conditions along the edges perpendicular to the direction of flowing stream may have essential (both qualitative and quantitative) influence. For the rest of values of the ratio $b / a$ the mixed boundary conditions in the plane have only quantitative influence on the dependence «amplitude-frequency». 
At the end, let's present some in our opinion most important new results obtained in this study. They are the result of the influence of boundary conditions on the dependence «amplitude-frequency» of nonlinear flutter of rectangular plates. For clarity and visibility, let's note once again that the dependence of the frequency of non-linear oscillations of the plate on the amplitude in absence of flowing stream has hard character, i.e. with the increasing amplitude of oscillation the frequency increases. In the present study we found that:

- The character of the dependence «amplitude-frequency» $A(\theta)$ is a two-valued at the certain intervals (closed or semi-infinite) of frequency variation, in particular it is identical to the nature of this dependency in the case of non-linear own oscillations of the shells;

- The kind of fixing of plate's edges in its plane may significantly change the character of the dependence $A(\theta)$, when the plate is elongated in the direction perpendicular to the

flow speed. If the plate is elongated in the direction of flow, the influence of the kind of fixing of plate's edges in its plane is only quantitative.

- Transition from one type of the dependence «amplitude-frequency» to another can be adjusted (up to the impossibility of excitation of such oscillations) setting the magnitude of the speed of flowing stream and changing the boundary conditions, and by the appropriate selection of the geometrical and physical parameters of the aeroelastic system.

\section{REFERENCES}

1. Baghdasaryan G.Y., Mikilyan M.A. Saghoyan R.O. Non-linear flutter of orthotropic rectangular plate. Collection of scientific papers of the international conference. Actual problems of continuum mechanics, 2010, Vol.1, pp.118-123.

2. Baghdasaryan G.Y., Mikilyan M.A. \& Marzocca P. On the Stability of Flexible Orthotropic Rectangular Plate in Supersonic Flow: Amplitude-Speed Dependency in Pre- and Post- Critical Flight Conditions. Journal of Aerospace Engineering, 10.1061/(ASCE)AS.1943-5525.0000246 (Jul. 19, 2012), ISSN: 0893-1321, 2012.

3. Baghdasaryan G.Y. On the stability of orthotropic shells in supersonic gas flow. //Izv.AN USSR OTN Mechanics and Engineering. 1961, №4, pp. 92-98.

4. Baghdasaryan G.Y., Mikilyan M.A., Saghoyan R.O., Marzocca P. Influence of Supersonic Flow on the Character of Amplitude-Frequency Dependency of Nonlinear Oscillations of Flexible Plate. //Proc. NAS RA. Mechanics. 2013. V.66. №3. pp.24-37.

5. Baghdasaryan G.Y., Mikilyan M.A., Saghoyan R.O. Character of Amplitude-Frequency Dependency of Nonlinear Oscillations of Flexible Plate at Critical Speeds. //Applied Mathematics and Mechanics, Gyumri, 2014, Vol.A, №1, pp. 20-39.

6. Baghdasaryan G.Y., Mikilyan M.A., Saghoyan R.O. Influence of supersonic gas flow on the amplitude of non-linear oscillations of rectangular plates.///Proc. NAS RA. Mechanics. 2016. V.69. №4.

\section{About author:}

Saghoyan Rafayel Onik - Freelance employer, Institute of Mechanics NAS RA Phone: (093) 248226; E-mail: rafael1984@mail.ru. 